\title{
Research on Talents Training in Higher Vocational Colleges for Intelligent Manufacturing
}

\author{
Cao Jiqing ${ }^{1, a}$ \\ ${ }^{1}$ School of Information Engineering, Suzhou Industrial Park Institute of Service Outsourcing, Suzhou, China \\ a george.cao@siso.edu.cn
}

Keywords: intelligent manufacturing; higher vocational education; talent training; training program

\begin{abstract}
With the "Made in China 2025" put forward, China's Manufacturing Industry continues to promote intelligent upgrading. New technologies, systems and manufacturing patterns lead to the emergence of new professional positions and changes in the connotation of professional positions. This paper discusses the cultivation of Intelligent Manufacturing Talents in higher vocational colleges, puts forward the basic rules on vocational education, innovates the talent development system, promotes the synchronization between the professional setting and the industry development, calls the industries and enterprises to participate in personnel training, enhances the key ability and quality of the Manufacturing Industry Talent, so as to cultivate the talents with high skills, innovation ability and artisan spirit required by the Intelligent Manufacturing Industry.
\end{abstract}

\section{Introduction}

The Manufacturing Industry reflects the level of national economic development and the level of scientific and technological development, which determines the rise and fall of a country and the international competitiveness. Western developed countries attach great importance to the world with advanced Manufacturing Industry of the real economy, they rely on automatic production and intelligent manufacture, seize the high-end manufacturing market, continue to maintain a leading edge of the Manufacturing Industry in the new round of industrial revolution.

"Made in China 2025" is a strategic choice to adapt to the trend of world economic development and change to "Manufacturing Power". As the top-level design planning and route map of China Manufacturing Industry in the next 10 years, it is the theme of the development of innovation driven manufacturing, the main direction and breakthrough with the Intelligent Manufacturing. [1]

\section{Essential Features of Intelligent Manufacturing}

The features of Intelligent Manufacturing are embodied in three aspects: [2]:

\subsection{Data Oriented}

Through timely and accurate collection of production data, such as production process, safety control, product quality and so on, it can achieve the visualization of the production. Real-time processing results are obtained for all data processing, the states are confirmed from personnel, the post-test are upgraded to the timely adjustment of function according to the processing process changes, which improve controllability of the production process, and realize information and the intelligentization of the process.

\subsection{Digital Twins}

By means of digital simulation, it can realize the real-time analysis, evaluation and decisionmaking with the acquired state information of the manufacturing process, establish the virtual model of the production process, realize the autonomous learning and decision control of machining process, and change the design process from the empirical test based decision-making to the rigorous scientific based decision-making. All the processes and performance data can appear transparent, which makes the manufacturing process be intelligently designed and planned in real 
time so as to realize the intellectualization and knowledge of process design.

\subsection{Flexible Production}

In the manufacturing process, three core technologies of the real-time sensing, comprehensive analysis and control, and instruction execution drive, manage all equipment and operation personnel, equipment and equipment, equipment and system into a unified network, realize the "Production Process Network" of the workshop. In the discrete manufacturing process, it can realize the automatic production scheduling, automatic loading and unloading scheduling of the workpiece, materials and cutting tool. In the case of automated production lines, production process management system can be remotely checked, the production tasks emergent or slow can be dynamically adjusted real time; If the unexpected problems happen in the production, it can be solved instantly and the production can be recovered automatically.

\section{Present Situation and Main Problems of Talent Training}

As the transformation and upgrading of the Manufacturing Industry in the era of smart, both higher vocational colleges as a skilled talents training base and training mode for the traditional talent training are out of touch with the requirements of the Intelligent Manufacturing Industry. To cultivate the qualified skilled talents in the new era of the work is still a long way to go. [3]

\subsection{Goal of Talent Training is not Precise Enough}

Facing the new development trend of "Intelligent Manufacturing", it is necessary to cultivate the compound skilled personnel who know information technology, mechanical and electrical equipment, automation, and are familiar with the industrial chain, innovation, management and service. Vocational colleges don't investigate timely in the construction process of Intelligent Manufacturing related specialty, or analysis of the changes of corporate jobs, resulting in graduates do not have the ability for Intelligent Manufacturing jobs, especially cannot meet the capacity requirements for the technology update, technological transformation, technology upgrading, industrial restructuring and upgrading of the enterprises.

\subsection{Content of Education is Out of Line with Demands of Actual Jobs}

The training of talents in Intelligent Manufacturing should reflect the needs of the development of regional economic pillar industries. Following the development direction of the new industry, the talents trained in vocational education should meet the needs of the industry, the development of the enterprise, and should develop moderately in advance on the basis of satisfying the ability of the position.

In the information era of rapid development, the pace of the overall professional talents training lags behind the development of the industrial upgrading and the society, and do not adapt to the "Internet+" era. The "Robot", "3D printing", "Cloud Computing", "Big Data" and "Virtual Reality" and other emerging IT technologies have not been used in the vocational education. The content of teaching is to train the talents that are urgently needed at the moment, but after a few years of the students' graduation, the enterprise's industry will have been transformed and upgraded, the supply of talent will lag behind the demand of enterprise posts, so the training of talents is lack of foresight.

\subsection{Quality of teachers Should be Improved and Teaching Methods Should be Innovated}

The new technologies required for Intelligent Manufacturing change the content and mode of transmission of knowledge in Vocational education. At present, the construction of Intelligent Manufacturing Specialty in Higher Vocational Colleges focuses on imparting knowledge and despising ability in the teaching mode. In the composition and structure of teachers, "Dual Teacher" is less, and professional teachers cannot effectively guide practice teaching. In the teaching environment, there is no training room for Intelligent Manufacturing technologies in the school, and there is no practice base for cooperation between schools and enterprises in the enterprises. 


\section{Urgent Need of Intelligent Manufacturing for Skilled Personnel}

The implementation of Intelligent Manufacturing should focus on the manufacturing technology and manufacturing management. Intelligent Manufacturing process presents multi-disciplinary knowledge integration, complex technology and technology integration status in the enterprise. It shows as the interlinked endpoints of the production enterprises, suppliers, distributors and users of the industry chain outside the enterprise and promote the reconstruction of the production mode, production organization and industry shape, so the development of the Intelligent Manufacturing needs all-round talents.

\subsection{Intelligent Manufacturing Changes Production Patterns}

Each link of the traditional transmission of the production process is discrete, the information among the people post matching, machine operation, material management, safety and other aspects cannot be transmitted efficiently, once the system is abnormal, each link cannot be coordinated, it will bring great losses to the enterprise.

Intelligent Manufacturing model is based on the industry data as the core, it can simulate to complete the process of programming, design, processing, assembly, debugging. The technologies of artificial intelligence, network and the new generation of information link all aspects of the whole production processes together through the network. The production process is adaptive, selfdecision, self-diagnosis and self-repair, which reduce the influence of uncertain factors, and the stability of the production process is higher.

\subsection{Intelligent Manufacturing Changes Job Settings and Requires Complex Skills}

\subsubsection{Intelligent Manufacturing Develop Intelligent Equipment}

The establishment of intelligent and digital factory workshop needs robot, talent with application technology and the complex talents with the ability of maintenance, operation and programming skills for the robots. It also needs the professional talents for intelligent equipment operation, commissioning, maintenance and improvement of expertise in manufacturing.

\subsubsection{Intelligent Manufacturing Realize Intelligent Production}

The automation and intelligence of the Intelligent Manufacturing make the traditional large-scale production line be replaced, the simple operator be eliminated and realize the production of unmanned machine operation. The worker should not only master the technical skills, but also need to have the ability of management and to solve the problem of the intelligent system. They need to become compound talents in operation, technology and management in one.

\subsection{Urgent Demand of Intelligent Manufacturing for Compound Skilled Personnel}

Intelligent Manufacturing needs more people to control "smart machines". In the process of Intelligent Manufacturing, the people have the responsibilities of installation, maintenance, programming and modification. The nature of the work is changed from operation to coordination and evaluation. And as the industry chain continues to expand, the vocational education is more urgent to train high-quality skilled personnel as the support of the Intelligent Manufacturing.

\section{Training Mode of Professional Talents in the Context of Intelligent Manufacturing}

Intelligent Manufacturing has fully integrated the advanced technologies, independent of the labour organization structure and the wisdom of the people. It has achieved the vertical integration of manufacturing process; the producers should not only have a rich knowledge of the product, but also have the ability to cross discipline. The producer need not only understand process parameters of product orders and the product drawings, but also correctly adjust the machine and the resolve the mistakes in the process of the manufacturing, so it requires higher vocational and high-quality talents with the characteristics of "Intelligent Manufacturing". 


\subsection{Training Qualified Personnel to Meet the Requirement of Intelligent Upgrading of Production Equipment}

With the usage of technologies of computer, control and advanced manufacturing, Intelligent Manufacturing led to the change of the production mode and the structure, the manufacturers should adapt to the upgrading of the infrastructure equipment, master the new production process, independently operate the various of intelligent equipment for operation and maintenance. Therefore, the talents trained in vocational education should have the application ability of basic, technical knowledges, consummate operation skills, strong post adaptation and innovation.

\subsection{Train Qualified Personnel in Line with the Transformation and Upgrading of Intelligent Manufacturing Industry}

Through interconnection to the information technologies of Cloud Computing, Big Data and Automation, Intelligent Manufacturing achieves the vertical integration between workers and the equipment in factories, the end-to-end integration between the different stakeholders on the industrial chain, and the horizontal integration between enterprises of different industries [4] .

Higher vocational colleges should reform the personnel training program, build a theoretical teaching system and a practical teaching system to adapt to the development of advanced manufacturing technology, and constantly update the content of teaching. In addition to having the breadth and depth of professional knowledge and practical operation ability, students should also have the ability of innovation and development, and the skilled talents should be trained to keep up with the development of enterprise production technology.

\subsection{Create a Full Range of Lifelong Vocational Education Environment}

Intelligent Manufacturing is an interdisciplinary complex manufacturing model. The required expertise and operational skills involve different disciplines, and new challenges for front-line practitioners engaged in Intelligent Manufacturing are presented. Practitioners must have the ability to cope with industry convergence and sustainable career development, therefore, it is necessary to create a full range of life-long vocational education environment.

A full range of lifelong vocational education environment should be created; the training mode of the system of modern vocational education talents should be established. In the stage of basic education, comprehensive vocational literacy in primary schools should be developed through vocational of elementary education; In the stage of high vocational education, the students should be trained for the ability of job adaptability, composite skills, team communication and collaboration skills and service innovation, and the courses of vocational and the specialized guidance will be created; In the workplace, the state and society should vigorously publicize the models and examples of the industrial workers of the new era, and organize various skills competition activities; In the society, we should create the vocational education and training system of the higher vocational colleges, industry associations, manufacturing enterprises and training institutions etc., provide training of the in-service management for the employment and enterprise staff. [5]

\section{Conclusion}

In short, the implementation of "Intelligent Manufacturing" continue to promote the upgrading of China's Manufacturing Industry, leading to the emergence of new job positions and changes in the connotation of professional positions, enterprises face "equipment is easy, talent is hard to find" situation. The basic law is that the higher vocational education should follow the professional construction of Intelligent Manufacturing, give full consideration to the production equipment intelligent upgrade and adjustment of industrial structure, innovate the vocational education system of the Manufacturing Industry, so that the high-quality skilled talents are adapt to the new requirements for talent of the Intelligent Manufacturing. 


\section{Acknowledgements}

In this paper, the research was sponsored by "2017 Jiangsu Provincial University of Philosophy and Social Science Research Fund Project” (Project No. 2017SJB1953).

\section{References}

[1] Zhou Ji. Intelligent Manufacturing---Main Direction of “Made in China 2025” [J]. China Mechanical Engineering, 2015(17): 2273-2281

[2] Wang Youfa, Zhou Xianzhong. A Review of Research on Domestic and International Intelligent Manufacturing[J]. Forum on Science and Technology in China, 2016, (4)

[3] Peng Qibo. Practice and Research on connotation construction of characteristic specialty in Higher Vocational Education[J]. Journal of Taiyuan Urban Vocational College, 2016(8):9-11

[4] Zhao Fuquan, Liu Zongwei. Industrial Transformation Strategy for the Manufacturing Sector of China in the Tide of Industry 4.0[J]. Forum on Science and Technology in China, 2016, (1)

[5] Liu Ting. Reflections on the Operation and Maintenance of information technology Based on Industry 4.0[J]Information Technology \& Standardization.2015(6) 